\title{
Spatial Analysis of Soil Salinity in the Indus River Delta, Pakistan
}

\author{
Ghulam Shabir Solangi \\ U.S. Pakistan Centers for Advanced Studies in Water, \\ Mehran University of Engineering \& Technology, \\ Jamshoro, Pakistan \\ solangi_shabir@yahoo.com
}

\section{Muhammad Munir Babar}

U.S. Pakistan Centers for Advanced Studies in Water, Mehran University of Engineering \& Technology, Jamshoro, Pakistan

mmunirbabar.uspcasw@faculty.muet.edu.pk

\author{
Altaf Ali Siyal \\ U.S. Pakistan Centers for Advanced Studies in Water, \\ Mehran University of Engineering \& Technology, \\ Jamshoro, Pakistan \\ aasiyal.uspcasw@faculty.muet.edu.pk \\ Pirah Siyal \\ National Centre of Excellence in Analytical Chemistry, \\ University of Sindh, \\ Jamshoro, Pakistan \\ pirahaltaf@chemist.com
}

\begin{abstract}
Soil salinization is one of the most damaging environmental problems in coastal areas, including Indus River Delta (IRD). Due to the reduction of flow in the Indus basin, saline water from the Arabian Sea is intruding into the IRD and has degraded the agricultural lands drastically. Focusing on the gravity of the problem, the present study was designed to explore the spatial distribution of soil salinity in the IRD. Physicochemical analysis of $\mathbf{3 7 5}$ soil samples randomly collected from 125 different locations within the study area was used. Analysis revealed that for the top $0-20 \mathrm{~cm}$ of soil, about $66.4 \%$ of the samples had electrical conductivity (EC) values, and $\mathbf{7 2 . 8 \%}$ sodium content (ESP) values higher than the FAO guidelines. Similarly, for soil depth of $20-40 \mathrm{~cm}, 60.8 \%$ of the EC values, and $72 \%$ of ESP exceeded the safe limits. Finally, for $40-60 \mathrm{~cm}$ of soil depth, $56.8 \%$ of the EC values and $79.2 \%$ of the ESP values were higher than the safe limits. Spatial analysis revealed that more than $50 \%$ of the IRD samples were affected by soil salinity. Reduced freshwater flow and the entry of saline water into the delta may likely be the causes of soil salinity in the IRD.
\end{abstract}

Keywords-physicochemical properties; soil salinity; electrical conductivity; exchangeable sodium percentage; coastal areas; Pakistan

\section{INTRODUCTION}

Soil salinization is the process of accumulation of soluble salts on the soil surface and within soil root zone [1] which results in the formation of salt-affected soils [2]. In arid and semi-arid regions of the world, it is one of the most common land degradation processes [2] which impacts social, economic, and environmental growth [3-4]. Authors in [5] reported that in arid and semi-arid areas, soil salinization is a major geo-hazard. Globally, more than 950 million hectares of land are saltaffected [6], out of which about 43 million hectares are attributed to secondary salinization [7]. Authors in [8] reported that about one-third of the irrigated land is severely affected by salinity or is exposed to conditions that encourage soil salinization. Due to evaporation, salts transport to soil surface from saline water table through capillary rise [9]. Also, irrigation with saline water can develop soil salinity [10]. It adversely affects soil fertility, crop growth and yield, as well as groundwater quality. It changes the normal functioning of the soil-water-plant system, which reduces nutrient uptake and ultimately causes a significant reduction in crop productivity [11]. Remotely sensed data are widely used worldwide for analysis of soil salinity [12]. These data have great potential to detect soil salinity spatially and temporally [13], which can be used for input into ArcGIS to evaluate and delineate soil salinity. Currently, various geospatial techniques are used for the estimation of the spatial distribution of soil salinity throughout the world [14-15]. Authors in [16] determined the spatial variations of salinity in the soils of Alberta. They found kriging and cokriging tools of spatial distribution as suitable for EC estimation and sodium absorption ratio (SAR) in the soil. Author in [17] determined soil salinity and found geostatistical methods better than the use of empirical formulae/equations. Authors in [18] used three spatial techniques, cokriging, spilain, and IDW (inverse distance weighted) for delineating the spatial variations of soil salinity in Australia. They reported cokriging and spilain as the best techniques for determining soil salinity. Author in [13] argued that for the restoration of environmental degradation, information about the nature and spatial distribution of soil salinity is essential.

In coastal areas there is a constant passage of salts from seawater into the mudflats and marshy lands, which may influence salt movement to the inland soil [9]. The proximity of the salty groundwater to the surface of the soil and the intrusion of seawater are among the potential causes of soil salinity in these areas [19]. IRD is the world's seventh largest delta, located in the southern part of Sindh province of Pakistan. Due to diminishing river Indus flows and uncertain rainfall patterns, the supply of freshwater to Delta is significantly reduced. Thus, 
increasing salinity is a crucial issue of the IRD. Due to increasing soil salinity, most of the agricultural lands in the IRD are not suitable any more for agricultural production. Therefore, quantification and mapping of soil salinity dynamics is essential for better planning and soil reclamation processes and thus for the prevention of ecological degradation [2]. So far, spatial analysis of soil salinity in the IRD, Pakistan has not been conducted. The present study was thus conducted using ground truthing field data to assess the gravity of the problem. The spatial distribution of soil salinity in the IRD will provide an insight to policymakers, farmers, and agriculturists for ecological degradation prevention and restoration of the delta.

\section{MATERIALS AND METHODS}

\section{A. The Study Area}

The Indus Delta is located between longitude $67^{\circ} 40^{\prime} 01^{\prime \prime}$ and $68^{\circ} 14^{\prime} 04^{\prime \prime}$ and latitude $23^{\circ} 48^{\prime} 29^{\prime \prime}$ and $24^{\circ} 57^{\prime} 19^{\prime \prime}$ in southern Sindh Province, Pakistan (Figure 1). Most of the deltaic area lies within two administrative districts, Thatta, and Sujawal. The active area of the delta is about 0.6 million hectares [20], having 17 major creeks and numerous subordinate small creeks. It extends from Sir Creek in the East to the Phitti Creek in the West. The climate of the delta is arid, the delta receives an average of about $220 \mathrm{~mm}$ of rainfall annually. Once, all the creeks of the delta were active, but now due to insufficient and erratic river flows, only two creeks, i.e. Khobar and Khar get the freshwater [21]. As a result, the dynamic delta area has declined to just $10 \%$ of its original area [22]. About 1.76 million people live in the delta, most of them are uneducated and depend on agriculture and fishing. The main crops cultivated in the area include sugarcane, rice, wheat, cotton, and vegetables. The area has the $13^{\text {th }}$ largest arid-climate mangrove forest in the world [23]. The topmost soil layer is composed of sand (about $15 \mathrm{~m}$ ), followed by clay and bedrock [24]. Geomorphologically, a shallow aquifer system with variable thicknesses exists in the delta [25]. Once, the area was known for its richness; now it is considered one of the poorest zones in Pakistan.

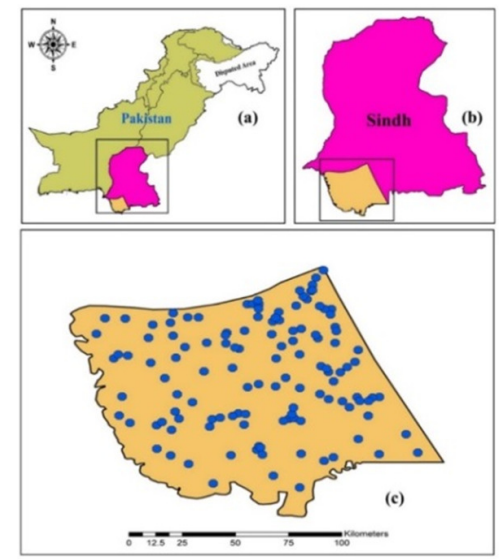

Fig. 1. GIS map of the study area and soil sampling locations

\section{B. Soil Sampling}

Georeferenced soil samples down to a depth of $60 \mathrm{~cm}(0-20$, $20-40$, and $40-60 \mathrm{~cm}$ ) were collected randomly from various locations of the delta. A soil auger was used for the extraction of soil samples. Their locations were recorded using a portable handheld Garmin GPS [26]. Sampling locations are shown in Figure 1(c). A total of 375 soil samples was collected from 125 different locations which were analyzed for various physicochemical parameters, namely texture, dry density, EC, $\mathrm{pH}$, and ESP.

\section{Physicochemical Analysis of Soil Samples}

In the present study, a hydrometer method and USDA textural triangle were used for the determination of textural classes of soil samples. The oven drying method was used to determine the dry density of the samples. The EC of soil saturation extract was determined at $25^{\circ} \mathrm{C}$ using a portable Hanna Model-8733, German EC meter. The EDTA titration method was used for the determination of calcium $\left(\mathrm{Ca}^{+2}\right)$, and magnesium $\left(\mathrm{Mg}^{+2}\right)$ cations in the soil. The soil $\mathrm{pH}$ was determined using a $\mathrm{pH}$ meter, and the sodium $\left(\mathrm{Na}^{+}\right)$ concentrations were extracted with ammonium acetate solution ( $1 \mathrm{~mol} / \mathrm{L})$ and were quantified according to [27]. The results of these chemical parameters were used to determine the SAR and calculate the ESP using the respective empirical formulas [27].

\section{Spatial Analysis Soil Salinity Mapping}

Based on the results of the analysis, the interpolated maps of soil texture and most of the soil salinity indicators i.e. EC, $\mathrm{pH}$, and ESP were prepared through ArcGIS 10.5 using the spatial analysis kriging and IDW approach. Based on soil salinity maps, the area of the IRD under salt-affected soils was determined.

\section{RESULTS AND DISCUSSION}

\section{A. Physicochemical Analysis of Soil Samples}

The statistical summary of the results of physicochemical parameters of soil samples in the form of minimum, maximum, mean, mode, standard deviation (STD), standard error of the mean (SE) and confidence error (CI) is depicted in Table I. The dry density at $0-20 \mathrm{~cm}$ of soil depth varied from 1.20 to $1.40 \mathrm{~g} / \mathrm{cm}^{3}$ with an average value of $1.30 \pm 0.02 \mathrm{~g} / \mathrm{cm}^{3}$. Similarly, at $20-40 \mathrm{~cm}$ depth, dry density varied from 1.19 to $1.44 \mathrm{~g} / \mathrm{cm}^{3}$ with an average value of $1.27 \pm 0.01 \mathrm{~g} / \mathrm{cm}^{3}$, while that at a depth of $40-60 \mathrm{~cm}$ it varied from 1.17 to $1.40 \mathrm{~g} / \mathrm{cm}^{3}$ with an average value of $1.26 \pm 0.01 \mathrm{~g} / \mathrm{cm}^{3}$. Analysis for soil texture revealed that loam and clay loam soils are the dominant textural classes in the top soil layer. About $37.8 \%$ of soil samples had loam, and $22.2 \%$ of soil samples had clay loam, $14.1 \%$ soil samples had clay, $8.9 \%$ had silty clay, $7.4 \%$ had silty clay loam, $5.9 \%$ had silty loam, $2.2 \%$ had sandy clay loam, $0.74 \%$ had sandy loam, and $0.74 \%$ had a sandy texture. Thus, most of soils of the delta have fine textural class. The coarse-textured sediment is deposited in the upper regions while the river brings sediment dominated with fine particles at the tail end. FFC [28] reported that the suspended sediment in river Indus below Kotri contains on average $5.0 \%$ sand, $49.6 \%$ clay and $45.4 \%$ silt, hence the alluvial soils of the delta are dominated by fine-textured soils. However, the lower soil layers, i.e. from 20 to $60 \mathrm{~cm}$ had almost similar soil texture distribution patterns. EC in $0-20 \mathrm{~cm}$ soil depth varied between 0.45 and $55.2 \mathrm{dS} / \mathrm{m}$ with an average of $14.28 \pm 2.45 \mathrm{dS} / \mathrm{m}$. The EC values at $20-40 \mathrm{~cm}$ were between 
0.56 to $48.0 \mathrm{dS} / \mathrm{m}$ with an average of $11.52 \pm 2.08 \mathrm{dS} / \mathrm{m}$. The soil is considered as saline, if its EC value exceeds $4 \mathrm{dS} / \mathrm{m}$ [29]. In this regard, in about $60.8 \%$ of the analyzed soil samples the EC values exceeded $4 \mathrm{dS} / \mathrm{m}$ indicating they were in the category of saline to highly saline soils. However, the EC in the soil samples collected at $40-60 \mathrm{~cm}$ depth varied from 0.66 to $41.8 \mathrm{dS} / \mathrm{m}$ with a mean of $9.57 \pm 1.75 \mathrm{dS} / \mathrm{m}$. About $56.8 \%$ of the soil samples at this depth had EC values greater than the FAO [30] guidelines. The soils having EC values of $0.7 \mathrm{dS} / \mathrm{m}$ or less are not stressful to most of the plants [31]. However, soil with an $\mathrm{EC}>0.7 \mathrm{dS} / \mathrm{m}$ causes problems for plants and many crop types. Generally, the soils having EC $>4 \mathrm{dS} / \mathrm{m}$ are considered as salt-affected soils witch were about the $61.0 \%$ of the collected soil samples. The spatial distribution of EC at various soil depths is portrayed in Figure 2. It is evident that the areas of the IRD which are nearer to the coast are more affected by soil salinity compared to those which are far from the coast, likely due to the impact of seawater intrusion in these areas.

TABLE I. SAMPLES PHYSICOCHEMICAL PARAMETERS

\begin{tabular}{|c|c|c|c|c|c|c|c|}
\hline Parameter & Min. & Max. & Mean & Mode & STD & SE & $\mathbf{C I}$ \\
\hline \multicolumn{8}{|c|}{ Soil depth $(0-20 \mathrm{~cm})$} \\
\hline $\begin{array}{c}\text { Dry density } \\
\left(\mathrm{g} / \mathrm{cm}^{3}\right)\end{array}$ & 1.20 & 1.40 & 1.30 & 1.28 & 0.05 & 0.004 & 0.02 \\
\hline EC (dS/m) & 0.45 & 55.2 & 14.28 & 11.76 & 13.98 & 1.25 & 2.45 \\
\hline pH & 6.8 & 11.42 & 7.93 & 7.5 & 0.58 & 0.05 & 0.10 \\
\hline ESP & 1.38 & 64.57 & 25.21 & 52.54 & 14.86 & 1.33 & 2.61 \\
\hline \multicolumn{8}{|c|}{ Soil depth $(20-40 \mathrm{~cm})$} \\
\hline Dry density & 1.19 & 1.44 & 1.27 & 1.27 & 0.04 & 0.004 & 0.01 \\
\hline EC & 0.56 & 48.0 & 11.52 & 13.78 & 11.86 & 1.06 & 2.08 \\
\hline pH & 7.1 & 9.2 & 7.99 & 7.5 & 0.43 & 0.03 & 0.07 \\
\hline ESP & 5.23 & 66.55 & 26.64 & 34.6 & 14.91 & 1.33 & 2.61 \\
\hline \multicolumn{8}{|c|}{ Soil depth $(40-60 \mathrm{~cm})$} \\
\hline Dry density & 1.17 & 1.40 & 1.26 & 1.27 & 0.04 & 0.003 & 0.01 \\
\hline EC & 0.66 & 41.8 & 9.57 & 2.36 & 9.98 & 0.89 & 1.75 \\
\hline pH & 7.2 & 9.21 & 8.01 & 7.7 & 0.43 & 0.038 & 0.07 \\
\hline ESP & 3.66 & 65.78 & 27.06 & 38.33 & 14.67 & 1.31 & 2.57 \\
\hline
\end{tabular}
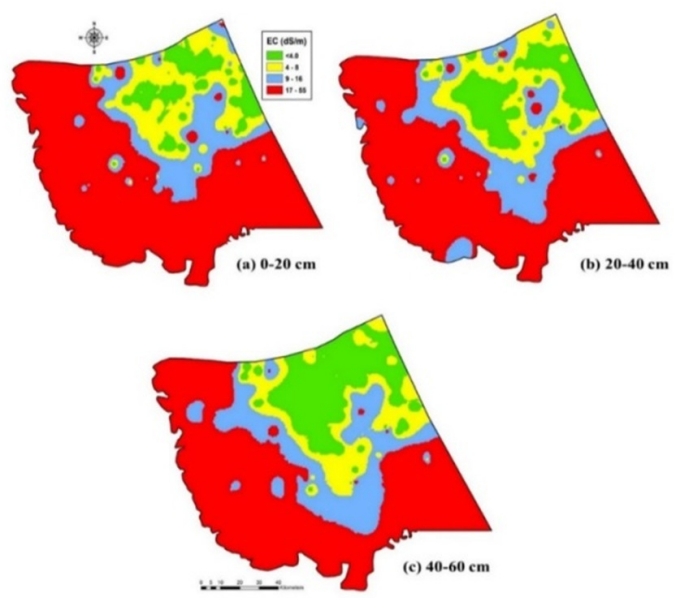

Fig. 2. EC spatial distribution in various soil depths

Hydrogen ion concentration $(\mathrm{pH})$ in the top $0-20 \mathrm{~cm}$ soil layer varied from 6.8 to 11.42 with a mean value of $7.93 \pm 0.10$, whereas, the $\mathrm{pH}$ of the $20-40 \mathrm{~cm}$ soil layer varied from 7.1 to 9.2 with a value of $9.99 \pm 0.07$. Finally, the $\mathrm{pH}$ of the $40-60 \mathrm{~cm}$ soil layer ranged from 7.2 to 9.21 with an average of
$8.01 \pm 0.07$. Generally, the soils having a $\mathrm{pH}>8.5$ are considered salt-affected (the soils with a $\mathrm{pH}>7.0$, to the most extreme of 14.0 , reflect increasing alkalinity). In the study area, most of the sampled soils (about $83.0 \%$ ) had $\mathrm{pH}$ values within the range of 8.5. The ESP values in the top $0-20 \mathrm{~cm}$ of soil depth in the study area ranged from 1.37 to 65.58 with an average of $25.21 \pm 2.6$. About $79.2 \%$ had ESP $>15$ and are classified as saltaffected soils. At $20-40 \mathrm{~cm}$, the ESP values ranged from 5.23 to 66.55 with a mean of $26.64 \pm 2.61$. About $72.8 \%$ of soil samples had ESP $>15$. The ESP values at the $40-60 \mathrm{~cm}$ soil depth ranged from 3.66 to 65.78 with an average of $27.06 \pm 2.57$ and about $74.6 \%$ of the samples had ESP $>15$. Figure 3 shows the spatial distribution of ESP in the soil samples. The maps portrayed that the samples collected from the areas nearer to the coast possessed higher ESP values.
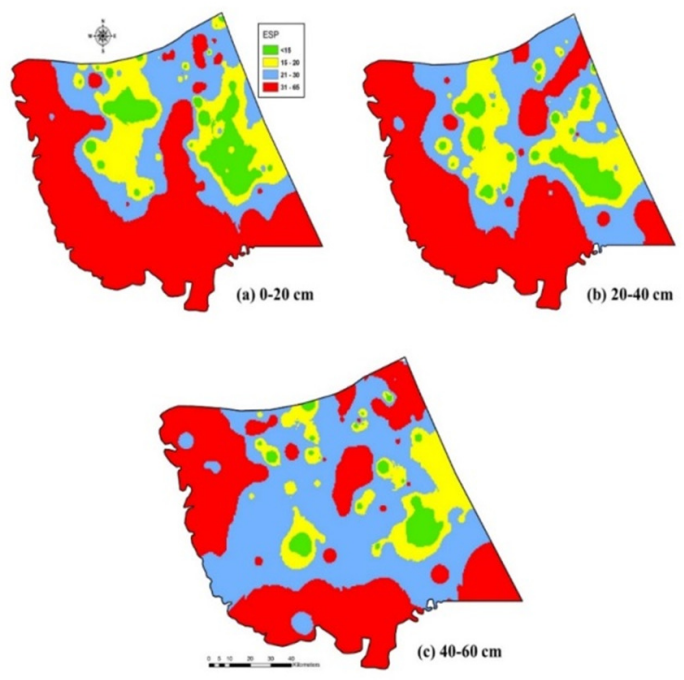

Fig. 3. ESP spatial distribution thematic maps for at various soil depths

Overall, the study revealed that the EC of $57-66 \%$ of the soil samples collected from $0-60 \mathrm{~cm}$ were beyond the permissible level of $4 \mathrm{dS} / \mathrm{m}$. Similarly, the $\mathrm{pH}$ of $14-18 \%$ of the soil samples was higher than 8.5 , and about $73-79 \%$ of the analyzed soil samples possessed ESP values higher than 15 , which has been suggested by the FAO [30] as the limit for agricultural purposes.

\section{B. Soil Salinity Spatial Distribution Analysis in the IRD}

Based on ground field data, spatial distribution thematic maps for various soil classes, i.e., normal, saline, sodic, and saline-sodic soils for all the three soil depths were prepared (Figure 4). It is obvious that the soil salinity in the upper layer was higher than that in the subsoil, suggesting that the salts in the underlying layers transported upward and accumulated in the topsoil [9]. The spatial distribution soil salinity maps showed that more than $50 \%$ of the IRD soils were salt-affected. The strongest level of salinity was in those samples which were taken from the coastal regions of the Arabian Sea, which most likely occured due to seawater intrusion [32]. 

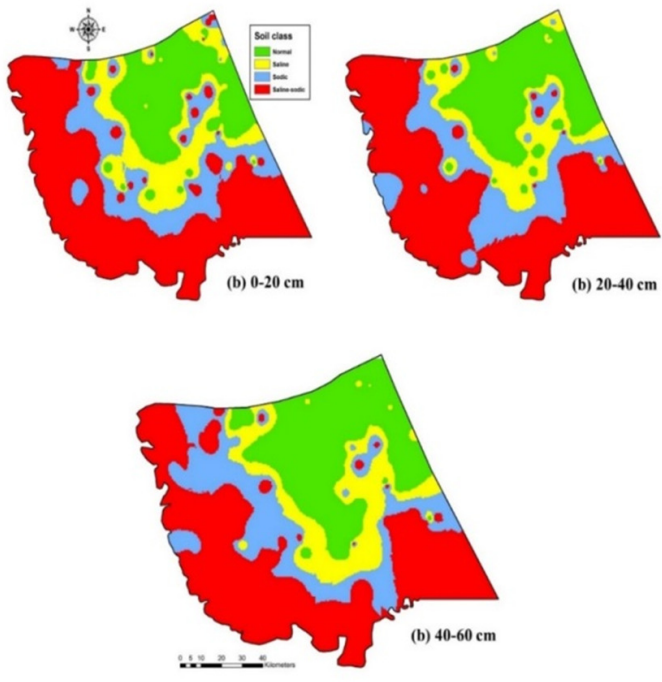

Fig. 4. Spatial distribution of soil classes to various depths

\section{CONCLUSIONS}

Physicochemical analysis of soil samples collected from different depths of various locations within the Indus delta revealed that about $66.4 \%$ and $72.8 \%$ of the samples collected from top $0-20 \mathrm{~cm}$ soil layer had EC and ESP values beyond the safe limits. Similarly, for soil samples collected from the 20$40 \mathrm{~cm}$ soil layer, $60.8 \%$, and $72 \%$, had EC and ESP values that exceeded safe limits. For the $40-60 \mathrm{~cm}$ soil layer, $56.8 \%$, and $79.2 \%$ had EC and ESP values higher than the safe limits. On an average, the dry density in the soil samples varied from 1.26 to $1.30 \mathrm{~g} / \mathrm{cm}^{3}$. Overall, spatial analysis of soil samples revealed that more than $50 \%$ of the IRD soils were affected by soil salinity. Reduction of the volume of freshwater flow in the Indus basin, low rainfall, seawater intrusion in the delta and various anthropogenic activities occurring along the coast are the most likely causes of degradation of soils in the IRD. The findings of this study are helpful to policymakers, farmers, and agriculturists in order to mitigate the ecological degradation in the Indus delta and revive its soils.

\section{ACKNOWLEDGEMENT}

Authors are extremely grateful to the U.S.-Pakistan Center for Advanced Studies in Water (U.S.-PCAS-W), Mehran UET, Jamshoro, Pakistan for funding the project entitled "Assessing the impact of Seawater Intrusion on Soil, Water, and Environment in the Indus Delta using GIS and RS". The project was funded by the U.S.-PCAS-W, under the applied research grants policy of the Center. We are also thankful to Dr. Rick Bereit, Professor, The University of Utah, United States of America (USA) for his constructive comments and suggestions.

\section{REFERENCES}

[1] A. A. Siyal, A. G. Siyal, Z. A. Abro, "Salt Affected Soil Their Identification and Reclamation", Pakistan Journal of Applied Science, Vol. 2, No. 5, pp. 537-540, 2002
[2] E. Asfaw, K. V. Suryabhagavan, M. Argaw, "Soil salinity modeling and mapping using remote sensing and GIS: The case of Wonji sugar cane irrigation farm, Ethiopia", Journal of the Saudi Society of Agricultural Sciences, Vol. 17, No. 3, pp. 250-258, 2016

[3] S. Nawar, H. Buddenbaum, J. Hill, "Estimation of soil salinity using three quantitative methods based on visible and near-infrared reflectance spectroscopy: a case study from Egypt", Arabian Journal of Geosciences, Vol. 8, No. 7, pp. 5127-5140, 2015

[4] J. Wang, J. Ding, A. Abulimiti, L. Cai, "Quantitative estimation of soil salinity by means of different modeling methods and visible-near infrared (VIS NIR) spectroscopy, Ebinur Lake Wetland, Northwest China", PeerJ, Vol. 6, ArticleID e4703, 2018

[5] A. Abuelgasim, R. Ammad, "Mapping soil salinity in arid and semi-arid regions using landsat 8 OLI satellite data", Remote Sensing Applications: Society and Enviroment, Vol. 13, pp. 415-425, 2018

[6] E. I. Pankova, M. I. Gerasimova, T. V. Korolyuk, "Salt-affected soils in Russian, American, and international soil classification systems", Eurasian Soil Science, Vol. 51, No. 11, pp. 1297-1308, 2018

[7] FAO, "Extent and causes of salt-affected soils in participating countries. AGL: Global network on integrated soil management for sustainable use of salt-affected soils", 2000

[8] A. Abbas, S. Khan, "Using remote sensing techniques for appraisal of irrigated soil salinity", International Congress on Modelling and Simulation, pp. 2632-2638, Modelling and Simulation Society of Australia and New Zealand, 2007

[9] J. Yu, Y. Li, G. Han, D. Zhou, Y. Fu, B. Guan, G. Wang, K. Ning, H. Wu, J. Wang, "The spatial distribution characteristics of soil salinity in the coastal zone of Yellow River Delta", Environmental Earth Sciences, Vol. 72, No. 2, pp. 589-599, 2014

[10] C. B. Ahmed, S. Magdich, B. Ben Rouina, M. Boukhris, F. Ben Abdullah, "Saline water irrigation effects on soil salinity distribution and some physiological responses of field-grown Chemlali olive", Journal of Environmental Management, Vol. 113, pp. 538-544, 2012

[11] D. Alexakis, D. Gotsis, S. Giakoumakis, "Evaluation of soil salinization in a Mediterranean site (Agoulinitsa District-West Greece)", Arab Journal of Geosciences, Vol. 8, No. 3, pp. 1373-1383,2014

[12] A. Allbed, L. Kumar, Y. Y. Aldakheel, "Assessing soil salinity using soil salinity and vegetation indices derived from IKONOS high-spatial resolution imageries: Applications in a date palm dominated region", Geoderma, Vol. 230-231, pp. 1-8, 2014

[13] A. M. Saleh, "Evaluation of different soil salinity mapping using remote sensing indicators and regression techniques, Basrah, Iraq", Journal of American Science, Vol. 13, No. 10, pp. 85-89, 2017

[14] M. Zare-Mehrjardi, R. Taghizadeh-Mehrjardi, A. Akbarzadeh, "Evaluation of geostatistical techniques for mapping spatial distribution of soil ph, salinity and plant cover affected by environmental factors in southern Iran”, Notulae Scientia Biologicae, Vol. 2, No. 4, pp. 92-103, 2010

[15] S. K. Behera, A. K. Shukla, "Spatial distribution of surface soil acidity, electrical conductivity, soil organic carbon content and exchangeable potassium, calcium and magnesium in some cropped acid soils of India", Land Degradation and Development, Vol. 26, No. 1, pp. 71-79, 2015

[16] E. Hosseini, J. Gallichand, D. Marcotte, "Theoretical and experimental performance of spatial interpolation methods for soil salinity analysis", Transactions of the ASAE, Vol. 37, No. 6, pp. 1799-1807, 1994

[17] J. Mohammadi, "Evaluation and maping of soil salinity hazard in Ramhormoz area (Khuzestan) using disjungtive kriging", Iran Agricultural Research, Vol. 19, pp. 83-98, 2000

[18] T. P. Robinson, G. Metternicht, "Testing the performance of spatial interpolation techniques for mapping soil properties", Computer and Electronics in Agriculture, Vol. 50, No. 2, pp. 97-108, 2006

[19] T. Gorji, A. Tanik, E. Sertel, "Soil salinity prediction, and mapping using modern technologies", Procedia Earth and Planetary Science, Vol. 15, pp. 507-512, 2015

[20] N. A. Kalhoro, Z. He, D. Xu, M. Faiz, L. V. Yafei, S. Naimatullah, A. H. Bhutto, "Vulnerability of the Indus River Delta of the North Arabian Sea, Pakistan”, GlobalNEST International Journal, Vol. 18, No. 3, pp. 599-610, 2016 
[21] A. Inam, P. D. Clift, L. Giosan, A. R. Tabrez, M. Tahir, M. M. Rabbani, M. Danish, "The geographic, geological and oceanographic setting of the Indus River", in: Large Rivers: Geomorphology and Management, John Wiley \& Sons, 2007

[22] ADB, Sindh Coastal and Inland Community Development Project, Interim Report, Vol. II, TA 4525-PAK, Asian Development Bank, 2005

[23] S. Majeed, S. B. Zaman, I. Ali, S. Ahmed, "Situational Analysis of Sindh Coast-Issues and Options", Managing Natural Resources for Sustaining Future Agriculture, Research Briefings, Vol. 2, No. 11, pp. 123, 2010

[24] A. Alamgir, M. A. Khan, J. Schilling, S. S. Shaukat, S. Shahab, "Assessment of groundwater quality in the coastal area of Sindh province, Pakistan", Environmental Monitoring and Assessment, Vol. 188, pp. 78-90, 2016

[25] S. A. Bablani, S. A. Soomro, "Evaluation of Seawater Intrusions in Left Bank Bediments of Coastal District Thatta, Sindh, Pakistan", 1st SWIMSWICA Joint Saltwater Intrusion Conference, Cagliari, Italy, September 24-29, 2006

[26] G. S. Solangi, A. A. Siyal, M. M. Babar, P. Siyal, "Evaluation of surface water quality using the water quality index (WQI) and the synthetic pollution index (SPI): a case study of Indus Delta region of Pakistan", Desalination and Water Treatment, Vol. 118, pp. 39-48, 2018

[27] L. G. M. Pessoa, M. B. G. dos S. Freire, B. P. Wilcox, C. H. M. Green, R. J. T. De Araujo, J. A. Filho, "Spectral reflectance characteristics of soils in northeastern Brazil as influenced by salinity levels", Environmental Monitoring and Assessment, Vol. 188, pp. 616, 2016

[28] FFC, Study on Water Escapages below Kotri Barrage to check seawater intrusion (Study-I), Final Report, Ministry of Water and Power. Government of Pakistan, 2005

[29] A. A. Hammam, E. S. Mohamed, "Mapping soil salinity in the East Nile Delta using several methodological approaches of salinity assessment", The Egyptian Journal of Remote Sensing and Space Science, available at: https://doi.org/10.1016/j.ejrs.2018.11.002, 2018

[30] FAO, Guidelines, Land Evaluation for Irrigated Agriculture, Soil Bull. No 55, FAO, 1985

[31] J. Kotuby-Amacher, R. Koenig, B. Kitchen, Salinity and Plant Tolerance, Utah State University, 2000

[32] H. T. Fourati, M. Bouaziz, M. Benzina, S. Bouaziz, "Modeling of soil salinity within a semic-arid region using spectral analysis", Arabian Journal of Geosciences, Vol. 8, No. 12, pp. 11175-11182, 2015 